|Araştırma Makalesi / Research Article |

\title{
Okul Öncesi Öğretmenlerinin Beyin Temelli Öğrenmeye Yönelik Görüşleri
}

\section{Preschool Teachers' Views on Brain-Based Learning}

\section{Betül Özaydın Özkara ${ }^{1}$}

\section{Anahtar Kelimeler}

Beyin temelli öğrenme Öğretmen görüşü Kuram oluşturma Öğrenme yöntemi Öğrenci merkezli öğrenme

\section{Keywords}

Brain-based learning

Teacher view

Grounded theory

Learning method

Student-centered

learning

\section{Başvuru Tarihi/Received}

25.04.2020

Kabul Tarihi /Accepted

13.08.2020
Öz

Bu çalışmanın amacı, okul öncesi eğitimde beyin temelli öğrenme yöntemi kullanan özel bir okulda öğretmenlerin beyin temelli öğrenme hakkındaki görüşlerini belirlemektir. Öncelikle belirlenen okulun haftalık programları incelenmiş, izlenen eğitim yönteminin beyin temelli öğrenme olduğundan emin olunmuştur. Türkiye'nin farklı illerinde şubesi bulunan okulun Akdeniz bölgesindeki kurumunda çalışan 10 okul öncesi öğretmen ile 2018-2019 Güz döneminde yarı yapılandırıımış görüşmeler yapılmıştır. Toplanan veriler kuram oluşturma yöntemi ile analiz edilmiştir. Analizler açık kodlama, eksenel kodlama ve seçici kodlama ile gerçekleştirilmiştir. Araştırma sonunda ideal öğrenme çıtısını etkileyen üç ana faktör olduğu belirlenmiştir. Bu değişkenler dıştan içe doğru; iklim, eğitim programı ve davranışlar olarak sıralanmaktadır. Davranış öğrencilerin eğitim sürecinde yapması gerekenleri, eğitim programı öğretmelerin bu süreçte uygulayacağı davranışları, iklim ise ortam ile ilgili durumları içermektedir. Değişkenlerin her biri bir alt katmanı doğrudan ya da dolaylı olarak etkilemektedir. Araştırma sonunda yapılan önerilerden bazıları şu şekildedir: öğrencilerin aktif katılımları teşvik edilmeli, öğrencilerin yaptıkları çalışmaları gerçek bağlamda deneyimleme fırsatı oluşturulmalıdır.

\section{Abstract}

The aim of this study is to determine the opinions of teachers about brain-based learning in a private school that uses brainbased learning method in preschool education. Firstly, the weekly programs of the determined school were examined and it was ensured that the education method. Institutions working in schools in the Mediterranean region with branches in different provinces of Turkey with 10 pre-school teachers during the 2018-2019 Fall semi-structured interviews were conducted. The collected data were analyzed by grounded theory. Analyzes were made with open coding, axial coding and selective coding. At the end of the research, it was determined that there are three main factors affecting the ideal learning outcome. These variables are from outside to inside; Climate, education program and behavior are listed. Behavior states what students should do during the education process. The education program is the behavior that teachers will apply in this process. climate includes conditions related to the environment.Some of the suggestions made at the end of the research are as follows: active participation of students should be encouraged and an opportunity should be created to experience their work in real context.

\footnotetext{
${ }^{1}$ Isparta Uygulamalı Bilimler Üniversitesi, Uzaktan Eğitim Meslek Yüksekokulu, Isparta, Türkiye; https://orcid.org/0000-0002-2011-1352
} 



\section{Extended Abstract}

\section{Introduction}

The aim of this study is to determine the opinions of teachers about brain-based learning in a private school that uses brain-based learning method in preschool education. In order to realize this aim, the weekly programs of the determined school were examined first. It was ensured that the training method followed was brain-based learning. Then, the opinions of the teachers were examined. It is known that creating a suitable environment is a prerequisite for applying brain-based learning method. However, the people who will create this environment are teachers. Therefore, determining their opinions is very important. The study is extremely important since it cannot be considered independent from the teachers who have the greatest contribution in organizing the environment. Also, when the previous studies are examined, the limited number of studies to determine the opinions of teachers suggests that this study will contribute to the literature.

\section{Method}

Grounded theory was used in the study. 10 teachers who provided preschool education participated in the study. It ranges from 3-18 years of total working years. 5 of the participants have private experience only while the other 5 have both public and private school experience. Semistructured interview form developed by the researcher was used. While there were 30 questions in the first form of the form, after receiving 5 expert opinions, 16 questions were included in the form. The interviews were made face to face and recorded. The recorded data have been converted into written form. Analysis, on the other hand, was open coding, axial coding and selective coding to the grounded theory framework.

\section{Result and Discussion}

Open coding; It consists of 3 categories: information, application and evaluation. In the information category, there are sub-categories of learning, education process and post-education. Most of the brain lobes were expressed in the learning sub-category. Permanent learning and reality adaptation are emphasized in the education process category. The 12 subcategories in the application category are as follows: general activities, deficiencies, right / left lobe, transition to new subject, method / technique and appeal to different senses, self-development, feedback, supporters of the brain, emotion control, permanent knowledge and class design. In the general category, it was determined that all of the teachers implemented an integrated program, made predictive activities, $90 \%$ of them were paying attention to connect, and $80 \%$ of them were practiced. While moving on to the new topic, it was seen that all of the teachers used environmental arrangement and estimation method. The collaborative method was expressed as the most used method. The visual sense is chosen as the most commonly heard sense organ. Teachers prefer to read the most to improve themselves. It was observed that most of the teachers pay attention to the class ventilation, water drinking encouragement and healthy nutrition speeches to support the students' brain. It was observed that the teachers firstly investigated the cause of the event while providing emotional control over the negativities experienced by the students. In order to keep the information permanent, paying attention to active participation takes the first place. When designing the class, suitable light is seen as the most important element. The evaluation category expressed in open coding consists of sub-categories as contribution of different methods, advantage and disadvantage. It was seen that all teachers expressed permanent learning as an advantage. The disadvantage was expressed only by 3 teachers that the preparation time was too high. With axial coding, categories and codes have been rearranged. Relationships between the codes have been revealed. Accordingly, many codes have been identified with each other. In the selective coding, ideal learning outcome was determined as the core category. Of the climate factor; It turned out that it affects the ideal learning outcome, behaviors and curriculum, and the curriculum reflects on the behavior.

In the study, data collected through interviews were analyzed by open coding, axial coding and selective coding. As a result of the analyzes, pre-school teachers' thoughts on brain-based learning were determined.

As a result of open coding; Three main categories are identified: information, implementation and evaluation. There is not much explanation at the level of knowledge. The codes that stand out in the application category are as follows: The use of integrated program, the students to predict the subjects, to inform them about the transition to the new subject and to make environmental arrangements in transition to the new subject are made by all teachers. It is seen that the methods and techniques used are mostly based on cooperative learning. It has been determined that teachers pay attention to address different senses and the most visual and tactile senses are addressed. The teachers stated that they supported the students on healthy and balanced nutrition and drinking water. Similarly, the importance of nutrition was emphasized in different studies (Halterman, Kaczorowski, Aligne, Auinger, \& Szilagyi, 2001; Jensen, 2005). Among the advantages of this method, it is seen that permanent learning, addressing everyone and providing experience opportunity are the first ones that come to mind. It has been observed in different studies that there are situations similar to the codes specified in open coding (Kaufman et al., 2008; Connell, 2005). In axial coding, associations were made between the codes. At this stage, the codes are combined in the following categories: General items, emotions, climate, interaction, educational outcome, teacher. Many categories appear to be interrelated. It was determined that each category affected the educational outcome. In the application of general principles, it has been determined that general principles, which are influenced by climate and emotions, are reflected in emotions and interaction. In selective coding, 3 factors affecting the ideal learning outcome were identified. It has been determined that student behaviors, curriculum and climate are effective in the ideal learning outcome. Climate has an impact on behavior and training program. In addition, it was determined that the training program had an effect on the behavior.

As a result, there are basic procedures that need to be done for students to reach the ideal learning outcome according to the thoughts of preschool teachers. In order to achieve this goal, students are required to actively participate, to experience, to establish a connection between what they learn. Active participation is also among the requirements of a good learning environment (Dwyer, 2002). Mental repetition and coding can facilitate the transfer of information to long-term memory so that information can be transferred from short-term memory to longterm memory (Senemoğlu, 2011) In addition, teachers are expected to perform integrated learning, use different methods, make preparations while transitioning to a new subject, provide the necessary guidance to students, and provide positive feedback. It has been observed that there is a need to provide an enriched environment, make arrangements in class design, address different sensory organs and control student emotions. 


\section{GíRiş}

Öğrenme, insan beynini kontrol eden kimyasal ve biyolojik durumlarla ilişkilidir. Sınıflarda başarılı öğrenme ve öğretme için beynin güçlü yanlarını bilmenin önemli olduğu düşünülmektedir. Beyin temelli öğrenmeye (BTÖ) ilişkin bu inanç öğrencileri okulda ve yaşamda başarılı olmaya motive etmek için öğretimin temel bir bileşenidir (Hileman, 2006). BTÖ beynin anlaşılmasına yönelik prensiplere bağlı stratejilerin birleştirilmesi olarak ifade edilebilir (Jensen, 2008). Anlamlı öğrenme için öğrencilere rehberlik eder (Gozuyesil \& Dikici, 2014). BTÖ’nun amacı ezbere bilgiden, anlamlı öğrenmeye geçişi sağlamaktır. Bu ise birbiriyle ilişkili olan rahatlatılış uyanıklık, düzenlenmiş daldırma, aktif süreçleme bileşenlerini gerektirir (G. Caine ve Caine, 1989).

Rahatlatılmış uyanıklık; öğretmenin sınıf ortamında, önemli zorlama ile düşük tehdit hissini birleştirebilmesidir (R. N. Caine ve Caine, 1990). Araştırmalar, insanların kendilerini tehdit altında hissettiklerinde algılarının azaldığını göstermektir (G. Caine ve Caine, 1989). Öğrenme ancak bireylerin kendilerini, fiziksel, ruhsal ve duygusal olarak rahat hissettikleri zaman gerçekleşmektedir (Dwyer, 2002). Zorlama ise insanların güvenli bir şekilde risk almasını, kendilerini tamamen işe dâhil etmesini sağlar. Ayrıca bu aşamada kasların gevşediği, nefesin düzenlendiği ve stresin azaldığı gerçek aktivitelerin olması önemlidir (G. Caine ve Caine, 1989). Bireylerin öğrenme kabiliyetini duyguları etkilemektedir. İnsan beyni duygular ve akıl arasında iletişim kurmaya çalışmaktadır. Bu nedenle öğretmenlerin, öğrencilerin duygularına müdahale etmeden, zorlayıcı şekilde meşgul ettiklerinde öğrencilerin dikkatlerini çekmeleri daha mümkün görülmektedir (Connell, 2005).

Düzenlenmiş daldırmada (immersion); eğitim sürecinde bir öğrencinin gelişiminin çoklu, etkileşimli ve gerçek hayat bağlamında olabileceği anlamına gelmektedir. Düzenleme (orchestrated) deneyimlerin senkronize edilmesi ve bağlanmasıdır (G. Caine ve Caine, 1989). Aktif süreçleme soru sorma, gerçeği yansıtma gibi aktiviteler aracılığı ile öğrencinin öğrenmeyi içselleştirmesi, kişisel olarak anlamlandırmasıdır (R. N. Caine ve Caine, 1990). Kapsamlı öğrenmenin gerçekleşebilmesi için, tehditten uzak bir ortamın oluşturulması, çoklu öğrenme stratejilerinin dikkatli bir şekilde düzenlemesi, gerçek hayat deneyimlerinin sağlanması ve öğrenmeye engel durumların anlaşılabilmesi gerekmektedir (Nummela ve Rosengren, 1986).

R. N. Caine ve Caine (1990) BTÖ ilkelerini şu şekilde sıralamıştır:

- Beyin; düşünceler, duygular, hayal etme gibi farklı işlevlerin aynı zamanda gerçekleştirilebildiği paralel bir işlemcidir.

- Öğrenme nefes almak gibi fizyolojik bir olaydır. Engellenebilir ya da kolaylaştırılabilir.

- Anlam arayışı doğuştandır, durdurulamaz, sadece yönlendirilebilir ve odaklandırılabilir.

- Anlam arayışı, örüntüleme (patterning) ile oluşur. Etkili öğrenmeyi oluşturmak için anlam ve kişiyle ilgili modeller oluşturmak gerekir.

- Örüntülemede duygular önemlidir. Duygular, olayları kaydetme ve geri çağırmada önemli olduğundan hafıza için kritiktir.

- Beyin, parçaları ve bütünleri aynı anda algılar. Beyin farklı işlevlerden sorumlu olan sağ ve sol yarım küreden oluşmaktadır. Ancak eğitimcilerin beyin yarımkürelerinin bilgiyi düzenlemek için eşzamanlı eğilim gösterdiklerini dikkate alması gerekir.

- Öğrenme hem çevresel (peripheral) hem de odaklaşmış dikkati gerektirir. Öğretmen materyali organize etmeli, ses, sıcaklık, gürültü iyi ayarlanmalıdır.

- Öğrenme bilinçli ve bilinçsiz süreçleri içerir.

- Uzlamsal hafıza sistemi ve ezbere öğrenme sistemi olmak üzere iki farklı türde belleğimiz vardır. Ezbere öğrenme için fazla vurgu yapmak transferi kolaylaştırmaz, öğrenenlerin kişisel dünyalarının dikkate alınması önemlidir.

- Olgular ve beceriler uzamsal hafızada depolandığında daha iyi öğrenilir. Bu nedenle gerçek hayat etkinlikleri, gösteriler, projeler, alan gezileri, resimler, hikâyeler, metaforlar, drama son derce önemlidir.

- Karmaşık öğrenme zorlama ile zenginleşir, tehdit ile engellenir. Oluşturulan ortamda düşük tehdit, yüksek zorlama olmalıdır.

- Her beyin kendine özgü düzenlenmiştir. Her öğrenciye hitap edecek şekilde, çok yönlü, görsel, dokunsal ve işitsel düzenlemeler yapılmalıdır. Bireysel ilgiler dikkate alınmalıdır.

Beynin en iyi şekilde nası öğrenebileceğine odaklanan BTÖ okulda değiştirilemez programlarla gerçekleştirilemez (Jensen, 2008). BTÖ’nün uygulandığı sınıflarda, öğrenme öğretme sürecinde beynin fonksiyonları ve öğrenmedeki rolü dikkate alınır. Bu ortamda güven oluşturulur, zengin uyarıcılar ortama eklenir. Öğrenmenin gerçekleşmesinde direkt öğretim ve daha zorlayıcı deneyimler ile otantik öğrenmenin oluşması arasında bir denge sağlanır (Fogarty, 2002). Bu yöntem; öğrenenlerin bilişsel yapılarının gelişmesine ve öğrenmelerinin kolaylaşmasına yardımcı olan öğrenci merkezli bir yaklaşımdır (Thomas ve Swamy, 2014). Politano ve Paquin (2000) BTÖ ortamı oluştururken; bireylerin eşsiz olarak görülmesi, bireylerin duyguları, anlam oluşturmaları, çoklu yol oluşturma, beslenmenin önemi ve tehdidin ortamdan kaldırılması konularının dikkate alınması gerektiğini vurgulamışlardır. Her öğrenci benzersizdir ve önceden sahip olduğu bilgiler vardır. Öğrenmenin anlamlı olabilmesi ve en iyi öğrenmenin gerçekleştirilebilmesinin bir yolu daha önceki bilgiler ile bağlantılar kurmak, önceki bilgilerle başlamaktır. 
BTÖ ilkelerine göre, öğrencilerin öğrenmelerine yardımcı olacak zenginleştirilmiş bir ortam için öğrenmeye;

- fizyolojinin,

- $\quad$ sosyal etkileşimin,

- duygusal bağlantının,

- bilinçli ve bilinçdışı öğrenmenin,

- bireysel stillerin ve eşsizliklerin,

- hem ayrıntıları hem de daha geniş görünüşleri algılayabilme yeteneğinin,

- hem çevresel bağlamdan öğrenme hem de dikkat yeteneklerinin,

- biyografik olayları ve olaylardan bağımsız ezberleri öğrenme kapasitesinin dâhil edilmesi gerekmektedir. Ayrıca bu ortamda öğrencilerin gelişim basamaklarının ve değişimlerinin kabul edilmesi, onaylanması, ortamdaki tehdidin azaltılması ve öz yeterliliklerin arttırılması gerekmektedir (Kaufman vd., 2008).

Hileman (2006) ise BTÖ de deneyimin ve koşulların beyni nasıl etkilediği dikkate alındığı için sınıf ortamında şu düzenlemelerin yapılması gerektiğini ifade etmiştir:

- $\quad$ Etkinlikler farklı özellikteki öğrenciler için değiş̧erek devam etmeli

- Öğrenciler fiziksel olarak aktif olmalı

- Görseller kullanılmalı

- Yeni ve zıt deneyimler oluşturulmalı

- Öğrenme ortamında farklı renklerin kullanımı sağlanmalı

- Bilinçsiz öğrenmeler için sözsüz iletişime dikkat edilmeli

- İşbirliğine dayalı çalışma desteklenmeli

- Risk, heyecan, ivedilik ve zevk duygularını bilerek harekete geçiren öğrenme etkinlikleri oluşturulmalı

- Düşünme becerilerini geliştirmek için gerçek dünya problemleri sunulmalı

- Öğrencilerin bilgi toplamalarına, problemleri kavramsallaştırmalarına, sonuçları paylaşılmasına izin vermeli ve teşvik etmeli

- Farklı yöntemler kullanarak sıkıcı olmadan tekrar yapılmalıdır (Hileman, 2006).

Ancak edinilen bilginin tekrar edilmesi tek başına hatırlamada yeterli değildir. Bilginin kalıcılığının sağlanması için kodlama ve diğer bilgilerle ilişkilendirilerek anlamlı duruma getirilmesi yani örgütlemenin gerçekleştirilmesi gerekir (Açıkgöz, 2003). Yeni öğrenilen bilgiler önceki bilgilerle ne kadar sağlam ilişkilendirilirse, bellekte o kadar kalıcı olduğu bilinmektedir (Mastropieri ve Scruggs, 1998).

İnsan beyni sağ ve sol yarıküreden oluşmaktadır. Beynin sol yarıküresi baskın olan bireylerin mantıksal, sağ yarı küresi baskın olan bireylerin yaratıcı olduğu fikri eskide kalmıştır. Ancak genel olarak sol yarı küre, bilgileri bölümler halinde ve sırayla kullanma, dil ve yazı ile öğrenme eğilimindedirler. Sağ yarım küre, bilgiyi bütün olarak, rastgele sırayla ve mekânsal bağlamda kullanma eğilimindedir (Jensen, 2005). Farklı yarıküreler bilgiyi farklı şekilde işlese de hem sağ yarı küre hem de sol yarıküre eğitim sürecine dâhil edilirse öğrenmenin en iyi şekilde gerçekleştiği bilinmektedir (Sausa, 2001). İnsanların gerçekleştirdiği işlevleri, beynin farklı bölümleriyle ilişkilendirilmektedir ancak beyin bir bütün olarak çalışmaktadır (Politano ve Paquin, 2000). Bu nedenle öğretmenler her iki yarı küreye yönelik etkinlikler kullanarak dersi düzenlemelidir (Sausa, 2001).

BTÖ’nün gerçekleştirilebilmesi için öğretmenlerin uyması gereken birçok ilke ve sınıf içi düzenleme olduğu görülmektedir. Beyinle ilgili araştırmalar, sinirbilimi ile eğitim arasında yakın bir ilişki olduğunu belirlemiştir. Bu nedenle beyin temelli öğrenme ile ilgili öğrenme öğretme yönteminin gelişmesi gerçekleşmiştir (Willis, 2007). Bu alanda farklı çalışmalar yapılmıştır. Daha önce yapılan çalışmalara bakıldığında nicel ağırlıklı olduğu görülmektedir. Örneğin; BTÖ’nün başarıya etkisi (Erol ve Karaduman, 2018; Noureen, Awan, ve Fatima, 2017; Saleh ve Subramaniam, 2018; Shabatat ve Al-Tarawneh, 2016), başarı ve tutuma etkisi (Oktay ve Çakır, 2013; Uzezi ve Jonah, 2017), başarı ve bilginin kalıcılı̆ına etkisi (Özden ve Gültekin, 2008; Tüfekçi ve Demirel, 2009), öğrenci motivasyonu ve tutumuna etkisi (Akyurek ve Afacan, 2013), öğrenme motivasyonuna etkisi (Saleh, 2011), bu yöntem ile ilgili çalışmaların içerik analizi (Yasar, 2017; Tosun ve Yaşar, 2015) gibi çalışmalar yapılmıştır. Bunun yanı sıra, BTÖ stratejisinin uygunluğunu tespit etmek (Mastoni, Sumantri, ve Ibrahim, 2019), öğrencilerin yöntem hakkındaki görüşlerini belirlemek (Avcı ve Yağbasan, 2010; Koyuncu ve Erden, 2010), öğretmenlerin yöntem hakkındaki görüşlerini belirlemek (Palavan ve Demir, 2017) amacıyla da çalışmalar yapılmıştır. Daha önce yapılan çalışmalara bakıldığında öğretmen görüşlerini belirlemeye yönelik çalışmaların sınırlı olduğu görülmektedir. Bu çalışmada beyin temelli öğrenme yönteminin uygulanabilmesi için uygun ortamın oluşturulması gerektiği dikkate alınarak bu ortamı oluşturacak olan öğretmenlerin görüşlerinin belirlenmesi hedeflenmiştir. BTÖ’nün gerçekten uygulanabilmesi bu ortamı oluşturan öğretmenlerden bağımsız düşünülemeyeceği için çalışma son derece önemlidir. Öğretmenlerin yöntem hakkındaki görüşleri; yöntemi kullanma durumlarını, yönteme bakış açılarını göstereceği için yöntem hakkında farkındalığın oluşması ve yöntemi tercih eden birimlere yol gösterici olarak alana katkı sağlayacaktır. 


\section{YÖNTEM}

\section{Araştırmanın Modeli}

Çalışmada kuram oluşturma (gömülü kuram) kullanılmıştır. Gömülü kuram, araştırma sürecinde verilerin sistematik olarak toplanması ve analiz edilmesi ile veriden teori oluşturmayı ifade etmektedir. Araştırmacı önceki teorilerden değil verilerden yola çıkarak teori ortaya çıkarmaktadır (Strauss ve Corbin, 1990). Bu amaçla çalışma üç aşamada gerçekleştirilir:

- Verilerdeki kavramsal kategorileri belirlemek.

- Belirlenen kategoriler arasındaki ilişkiyi bulmak.

- Bu ilişkileri kavramsallaştırmak ve açıklamak.

Bu yöntemde kuram oluşturulurken mevcut verilerin tümevarımsal olarak kullanılması esas alınmaktadır (Punch, 2011).

\section{Çalışma Grubu ve Çalışmanın Yapıldığı Ortam}

Yapılan çalışma 2018-2019 Güz yarıyılında, okul öncesi eğitim veren 10 öğretmen ile gerçekleştirilmiştir. Öğretmenler çalışııkları okulda işe başladıklarında kullanılan yöntem ile ilgili eğitimler almışlardır. Okul öncesi eğitim bölümünün koordinatörü olan öğretmen belirli aralıklarla genel merkez tarafından eğitime tabi tutulmuştur. Sonrasında ise yapılan her eğitim hakkında okuldaki diğer öğretmenler ile bilgilerini paylaşmıştır. Verilen eğitimler göz önünde bulundurularak öğretmenlerin ilgili yöntem hakkında bilgi sahibi oldukları bilinmektedir. Öğretmenlerin deneyim yılı farklıık göstermektedir. Bulundukları okuldaki tecrübeleri 1-3 yıl arasında değişirken, toplam çalışma yıllarının 3 yıl (3 kişi), 4 yıl (5 kişi), 16 yıl (1 kişi) ve 18 yıl (1 kişi) olduğu belirlenmiştir. Öğretmenlerden 1 tanesi erkek diğerleri kadındır. Öğretmenlerin 5 tanesinin sadece özel okullarda çalıştığı, 5 tanesinin ise hem devlet okulunda hem de özel okullarda çalıştı̆ı belirlenmiştir. Araştırmanın yapıldığı okul özel bir eğitim kurumu olup Türkiye genelinde birçok şubesi bulunan ve okul öncesinde beyin temelli öğrenmenin benimsendiği ifade edilen bir kurumdur. Kurumda haftalık ders programları merkezden verilmekte ve tüm şubelerde aynı içeriğin kullanılması sağlanmaktadır. Çalışmaya başlamadan önce haftalık programlar ve yapılan aktiviteler incelenmiş ve kurumda gerçekten beyin temelli öğrenmenin uygulandığı tespit edilmiştir.

\section{Veri Toplama Aracı}

Literatür taraması yapıldıktan sonra araştırmacı tarafından yarı yapılandııııış görüşsme formu oluşturuluştur. 30 soru bulunan formun ilk hali 5 uzmanın görüşü alındıktan sonra 16 sorunun yer aldığı halini almıştır. Formdaki sorular BTÖ ile ilgili genel bilgiler (BTÖ deyince aklına ne geldiği, yöntemin avantaj ve dezavantajları, öğrenci ve öğretmen açııından yöntemin değerlendirilmesi gibi) süreçteki etkinlikler (etkinlikler BTÖ’yi nasıl destekliyor, yöntem ve strateji çeşitlilï̆i, geri bildirim verme şekli, bütünleştirilmiş program kullanımı, kalıcılık oluşturma yöntemleri gibi) beyni destekleyiciler (su içmeyi özendirme, beslenme, havalandırma gibi) ve ortam (farklı duyulara hitap, sınıf dizaynı gibi) ile ilgili bilgileri almaya yönelik oluşturulmuştur. Bu formun kullanıldığı görüşmeler yüz yüze olacak şekilde yapılarak katılımcıların izinleri dâhilinde kayıt altına alınmıştır. Yapılan görüşmeler süresince, gerçekleştirilen analizlerde sürekli karşılaştırmalar yapılarak gerekli olması halinde sorularda bazı değişikliklere gidilmiştir.

\section{Verilerin Toplanması ve Analizi}

Veriler yüz yüze yapılan görüşmeler ile toplanmıştır. Bu amaçla öğretmenlerden randevu alınmış ve 2018-2019 eğitim-öğretim yııının birinci döneminde derslerinin boş olduğu günlerde yaklaşık iki aylık süreç içerisinde veriler toplanmıştır. Her bir görüşme 50-60 dakika arasında tamamlanmıs ve dijital olarak kayıt altına alınmıştır. Kayıt altına alınan veriler yazılı hale getirilmiştir. Verilerin Times New Roman yazı stilinde 12 punto yazı büyüklüğü ve tek satır aralığında 38 sayfa ve 14884 sözcükten oluştuğu belirlenmiştir. Bu veriler gömülü teori kapsamında açık kodlama, eksenel kodlama ve seçici kodlama ile analiz edilmiştir. Verilerin isimlendirilmesi, kategorize edilmesi için açık kodlama, kodların birbiriyle ilişkilendirilmesi için eksenel kodlama, çekirdek bir kategori belirleyerek diğer kategorileri onunla ilişkilendirmek için seçici kodlama gerçekleştirilmiştir. Açık kodlama; verilerden kavramların ve kavramların özelliklerinin, boyutlarının belirlendiği analitik bir süreçtir. Bu sürecin ilk aşaması kavramsallaştırmadır. Kavramsallaştırmada araştırmacı; aynı durum, olay, olguyu aynı etiketlerle isimlendirmektedir. Daha sonra bunları bazı özelliklerini dikkate alarak sınıflandırmaktadır (Strauss ve Corbin, 1990). Eksenel kodlamada, neden ya da nasıl oldu, nerede, ne zaman, nasıl hangi sonuçlarla gibi sorularının cevabı aramakta ve bunu yaparken de kategoriler arasında ilişkiyi ortaya çıkarılmaktadır (Strauss ve Corbin, 1990). Seçici kodlamada ise üst soyutlama düzeyindeki merkezi kategori ayrıştırılarak ayrıntılı açıklama yapılmaktadır (Punch, 2011).

Çalışmada iç güvenirliği sağlamak amacıyla LeCompte ve Goetz (1982) belirttiği özelliklerden verilere yorum eklemeden doğrudan sunulması, veri analizinde kodlayııılar arası güvenirlik çalışmasının yapılması ve verilerin mekanik olarak kaydedilmesi 
sağlanmıştır. Açık kodlama aşamasında gerçekleştirilen kodlayıcılar arası güvenirliğin uzlaşma yüzdesi \%87 olarak belirlenmiş ve Miles ve Huberman’a (1994) göre güvenilir olduğu görülmüştür. Farklı olan kodlamalar üzerinde tartışılarak kodlamalar nihai halini almıştır.

\section{BULGULAR}

Yapılan analiz sonucunda açık kodlama gerçekleştirilmiştir. Bu kodlama sonucunda öğretmenlerin BTÖ ile ilgili sorulan sorular hakkındaki bilgi düzeyleri Tablo 1'de görüldüğü gibi bilgi kategorisinde toplanmıştır.

Tablo 1. Açık kodlama ile oluşturulan bilgi kategorisindeki kodlar

\begin{tabular}{|c|c|c|c|}
\hline Kategori & Alt Kategori & Kod & $\mathrm{n}$ \\
\hline \multirow[t]{9}{*}{ Bilgi } & \multirow{2}{*}{ Öğrenme } & Loblar & 8 \\
\hline & & Biyolojik yapı & 3 \\
\hline & \multirow{5}{*}{ Eğitim Süreci } & Farklı duyulara hitap & 5 \\
\hline & & Aktif katılım & 4 \\
\hline & & Gerçeğe uyarlama & 3 \\
\hline & & Sarmal yapı & 2 \\
\hline & & Zenginleştirilmiş ortam & 1 \\
\hline & \multirow{2}{*}{ Eğitim Sonrası } & Kalıcı öğrenme & 5 \\
\hline & & Yansıtma & 2 \\
\hline
\end{tabular}

Tablo 1'de yer alan bilgi kategorisinde, öğrenme, eğitim süreci ve eğitim sonrası olmak üzere üç alt kategori yer almaktadır. Öğrencilerin biyolojik yapıları sayesinde öğrendiği, sağ/sol lobların farklı alanlarda baskın olması nedeni ile farklı şekillerde öğrenmeyi gerçekleştirdikleri düşünülmektedir. Eğitim sürecinde öğretmenler en fazla $(n=5)$ farklı duyulara hitap ederek öğretim yapmaları gerektiğini bildiklerini dile getirmişlerdir. Bu şekilde gerçekleştirilen eğitim ile öğrencilerin kalıcı öğrenebileceği ve öğrendiklerini farklı alanlara yansıtabileceğini düşünen öğretmenlerin bulunduğu görülmektedir.

Farklı duyulara hitap ve kalıcı öğrenme ile ilgili K2 kodlu 18 yıllık kadın öğretmenin ifadeleri şu şekildedir:

“..Çocukların farklı duyu organlarına hitap ederek çocuğun öğrenmesini sağlamak ve eğitimi kalıcı hale getirmek yani her yönden direkt önce anlatarak değil de her yönden kokularına kadar, görmesini, dokunmasını sağlayarak öğrenmedir."

Öğretmenlerin eğitim sürecinde BTÖ ile ilgili yaptıkları uygulamalar Tablo 2'de görüldüğü gibi uygulama kategorisinde yer almaktadır. 
Tablo 2. Açık kodlama ile oluşturulan uygulama kategorisindeki kodlar

\begin{tabular}{|c|c|c|c|c|c|c|}
\hline Kategori & Alt Kategori & Kod & $\mathrm{n}$ & Alt Kategori & Kod & $\mathrm{n}$ \\
\hline & Genel olarak & Bütünleştirilmiş program & 10 & Duygu kontrolü & Nedenini araştırma & 8 \\
\hline & Yapılanlar & Tahmin & 10 & & Sakinleştirme & 4 \\
\hline & & Bağlantı kurma & 9 & & Etkinliğe çekme & 4 \\
\hline & & Deneyimleme & 8 & & Fiziksel temas & 3 \\
\hline & & Gerçeğe uyarlama & 4 & & Sınıftan uzaklaştırma & 2 \\
\hline & & Basitten zora & 2 & & Sakin kalma & 2 \\
\hline & & Zamanlama & 2 & & Barıştırma & 2 \\
\hline & Eksiklikler & Somutlaştırma & 2 & Geri bildirim & Olumlu geri bildirim & 9 \\
\hline & & Gerçek bağlamda deneyim & 1 & & Veli iletişimi & 2 \\
\hline & Sağ/sol lob & Dikkate almama & 5 & Kendini geliştirme & Okuma & 5 \\
\hline & & İlgi alanına yönlendirme & 4 & & Sosyal medya & 2 \\
\hline & & Çoklu alanda yönlendirme & 1 & & Okul eğitimlerine katılım & 2 \\
\hline & Yeni konuya & Yeni konuya geçiş bilgisi & 10 & Sınıf dizaynı & Uygun ışık & 8 \\
\hline & geçiş & Çevre düzenleme & 10 & & Isı ayarı & 6 \\
\hline \multirow{13}{*}{ Uygulama } & & Resim yapma & 2 & & Değiştirilebilir ortam & 3 \\
\hline & Yöntem/ Teknik & İşbirliğine dayalı & 7 & Beyni & Havalandırma & 8 \\
\hline & Kullanımı & Soru sorma & 6 & destekleyiciler & Su içmeye özendirme & 6 \\
\hline & & Beyin fırtınası & 4 & & Sağlıklı/dengeli beslenme & 6 \\
\hline & & Neden sonuç ilişkisi & 2 & & Dinlenme zamanı & 4 \\
\hline & & Olay analizi & 1 & & Ortam temizliği & 2 \\
\hline & & Farklı sembol & 1 & & Öğrencinin fiziksel temizliği & 2 \\
\hline & & İstasyon & 1 & & Havalandırma & 8 \\
\hline & Farklı duyulara & Görsel & 7 & Kalıcı bilgi & Aktif Katılım & 8 \\
\hline & hitap & Dokunma duyusu & 6 & & Tekrar etme & 5 \\
\hline & & İşitsel & 4 & & Anlamlı öğrenme & 5 \\
\hline & & Koku & 4 & & Bağlantı kurma & 5 \\
\hline & & Tat & 3 & & Görsel materyal & 2 \\
\hline
\end{tabular}

Yapılan analizde öğretmenlerin, BTÖ ile ilgili bilgi düzeyinde çok fazla açıklama yapmamalarına rağmen uygulama düzeyinde çok fazla işlem yaptıkları görülmektedir. Tablo 2'de uygulama kategorisi bulunmaktadır. Uygulama kategorisinde; genel olarak yapılanlar, eksiklik olarak görülen durumlar, sağ/sol lob için öğretmenlerin öğrencileri yönlendirme durumu, yeni konuya geçiş esnasında yapılanlar, öğretim sürecinde kullanılan yöntemler ve teknikler, farklı duyulara hitap, öğrencilerin adrenalin ve noradrenalin salgılaması durumunda duygu kontrolü için yapılanlar, öğrencilere verilen geri bildirim türü, öğretmenlerin kendini geliştirmek için yaptıkları, sınıf dizaynı, beyni destekleyici faaliyetler, bilginin kalıcı hale gelmesi için yapılanlar ve olmak üzere toplam 12 alt kategoriden oluşmaktadır. Öğretmenlerin hepsinin bütünleştirilmiş program, tahmin ettirme, yeni konuya geçiş bilgisini verme, çevreyi düzenleme kodlarını ifade ettikleri görülmektedir.

K5 kodlu 2 yıllık tecrübesi olan kadın öğretmenin bütünleşik program, tahmin, çevre düzenleme, kodları ile ilgili ifadeleri ağasıdaki gibidir:

"Bütünleşik etkinlikler yapıyoruz örneğin yeni temamıza gençtik. Mevsimler temasına, çocuğa tema tahmini yaptırdık. Sınıfımızı hazırladık, çocuk çevreyi fark ederek temayı tahmin etmeye çalıştı. Daha sonra mevsimler olduğunu biz söyledik. Ardından da sanat etkinliğine geçerek düşündüğünüzde sizin aklınıza ne geliyor. Bunu yaptırdık ardından da planımızda oyun etkinliği vardı oyun etkinliğinde dört mevsimde mesela yaz mevsiminde hangi sesler duyulur? Onu açtık dalga sesleri mesela, çocuğa gözlerinizi kapatın dedik. Ve bunu dinleyin, hangi mevsime ait olduğunu söyleyin, şeklinde bir soru sorduk..."

Yöntem/teknik kullanımı kategorisinde soru sorma, işbirliğine dayalı öğrenme kodları ile ilgili K9 kodlu 2 yıllık tecrübesi olan kadın öğretmenin ifadeleri ise şu şekildedir;

"Soru sorma tekniğini çok fazla kullanıyorum. Çünkü o yaş grubundaki çocuklara soru sorarak cevap vermelerini beklemek, nedenlerini beklemek onlarda çok merak oluşturuyor... İşbirlikçi yöntemi çok kullanıyorum. Çünkü bir çocuğun işbirliği içerisinde bir şeyleri tamamlaması onlar açısından çok büyük destekleyici bir şey aslında."

Farklı duyulara hitap kategorisinde koku kodu ile ilgili K1 kodlu 4 yıllık tecrübesi olan kadın öğretmenin ifadeleri:

“Ben kokunun öğrenmede çok faydası olduğunu düşünüyorum açıkçası. Örneğin; o gün deniz canlıları ile alakalı bir etkinlik yapılacağından sınıfa okyanus kokusu olan spreyi onlar gelmeden önce, sınıfa veriyorum..."

K3 kodlu 2 yıllık tecrübesi olan kadın öğretmenin beyin destekleyicileri kategorisinde yer alan havalandırma, sağlıklı/dengeli beslenme, dinlenme zamanı konusunda şunları dile getirmiştir:

"Benim özellikle dikkat ettiğim şey sınıfın havalandırılması. Yemek yeme konusunda çok fazla ısrarcı olmamakla birlikte sağlıklı beslenmenin yararlarından bahsediyorum, gün boyu bizim vücudumuzu yiyeceklerin idare etmesi gerektiğinden bahsediyorum. 
Bazen dinleme çalışmaları da yapıyoruz biz. Gözlerimiz kapatıyoruz ve dinleniyoruz gün içinde neler yaptığımız da düşünüyoruz, bazen uyuyakalan biri olabilir tabii."

Tablo 3 ise değerlendirme kategorisini içermektedir. Tablo 3'de farklı yöntemlerin katkısı, avantajlar ve dezavantajlar olmak üzere üç alt kategori yer almaktadır. K7 kodlu, 3 yılık tecrübesi olan kadın öğretmen bu yöntemin avantajları arasında kalıcı öğrenme, okulu sevdirme, merak uyandırma, öğretmeni mutlu etme kodlarını şu şekilde ifade etmiştir:

"Çocukların okulu sevmesini sağlıyor. Öğrencilerin merakla derse girmesini sağlıyor, zaten temalarımız değiştiği için yeni temada daha da heyecanlı oluyor öğrenciler için. Ayrıca öğrenmenin çok daha fazla kalıcı olduğunu görüyoruz. Bu yöntem bizim açımızdan da çok önemli, çocuk çünkü öğretmen olduğunuz için anlattığınız şeyin öğrenilmesi sonrasında çocuğa sorulduğunda onu çocuğun söylemesi sizi mutlu ediyor."

Bu yöntemin olumlu/olumsuz yönleri ile ilgili öğretmen görüşleri ise Tablo 3'de değerlendirme kategorilerinde toplanmıştır.

Tablo3. Açık kodlama ile oluşturulan değerlendirme kategorisindeki kodlar

\begin{tabular}{|c|c|c|c|}
\hline Kategori & Alt Kategori & Kod & $\mathrm{n}$ \\
\hline \multirow{13}{*}{ Değerlendirme } & \multirow{6}{*}{ Farklı Yöntemlerin katkısı } & Dikkat çekme & 5 \\
\hline & & Herkese hitap & 5 \\
\hline & & Yetenek geliştirme & 4 \\
\hline & & Kalıcı öğrenme & 2 \\
\hline & & Katılım artışı & 2 \\
\hline & & Öğretmende mutluluk hissi & 1 \\
\hline & \multirow{6}{*}{ Avantaj } & Kalıcı öğrenme & 10 \\
\hline & & Herkese hitap & 8 \\
\hline & & Deneyim firsatı & 7 \\
\hline & & Öğretmeni mutlu etme & 4 \\
\hline & & Okulu sevdirme & 1 \\
\hline & & Merak uyandırma & 1 \\
\hline & Dezavantaj & Hazırlık zamanı & 3 \\
\hline
\end{tabular}

Şekil 1'de görüldüğü gibi açık kodlamadan sonra yapılan eksenel kodlama ile kodlar ilişkilendirilmiştir.

Şekil1'de yer alan eksenel kodlamaya göre BTÖ ile ilgili genel ilkeler, sınıf ortamı ile ilgili kodlarından oluşan iklim ve öğrenci duygularından etkilenirken, genel ilkeler öğrenci duygularını, öğrencilerin gerçekleştirdiği etkinlik kodlarını içeren etkileşim ve eğitim sonrasında oluşan eğitim çıktılarını etkilemektedir. Sınıf iklimi eğitim çıktısını ve etkileşimi etkilerken, etkileşimin ve öğrenci duygularının eğitim çıktısına olan etkisi de görülmektedir. Duygular ve etkileşim ile eğitim çıktısı ve öğretmen ile ilgili durumlar arasında da çift yönlü bir ilişki tespit edilmiştir.

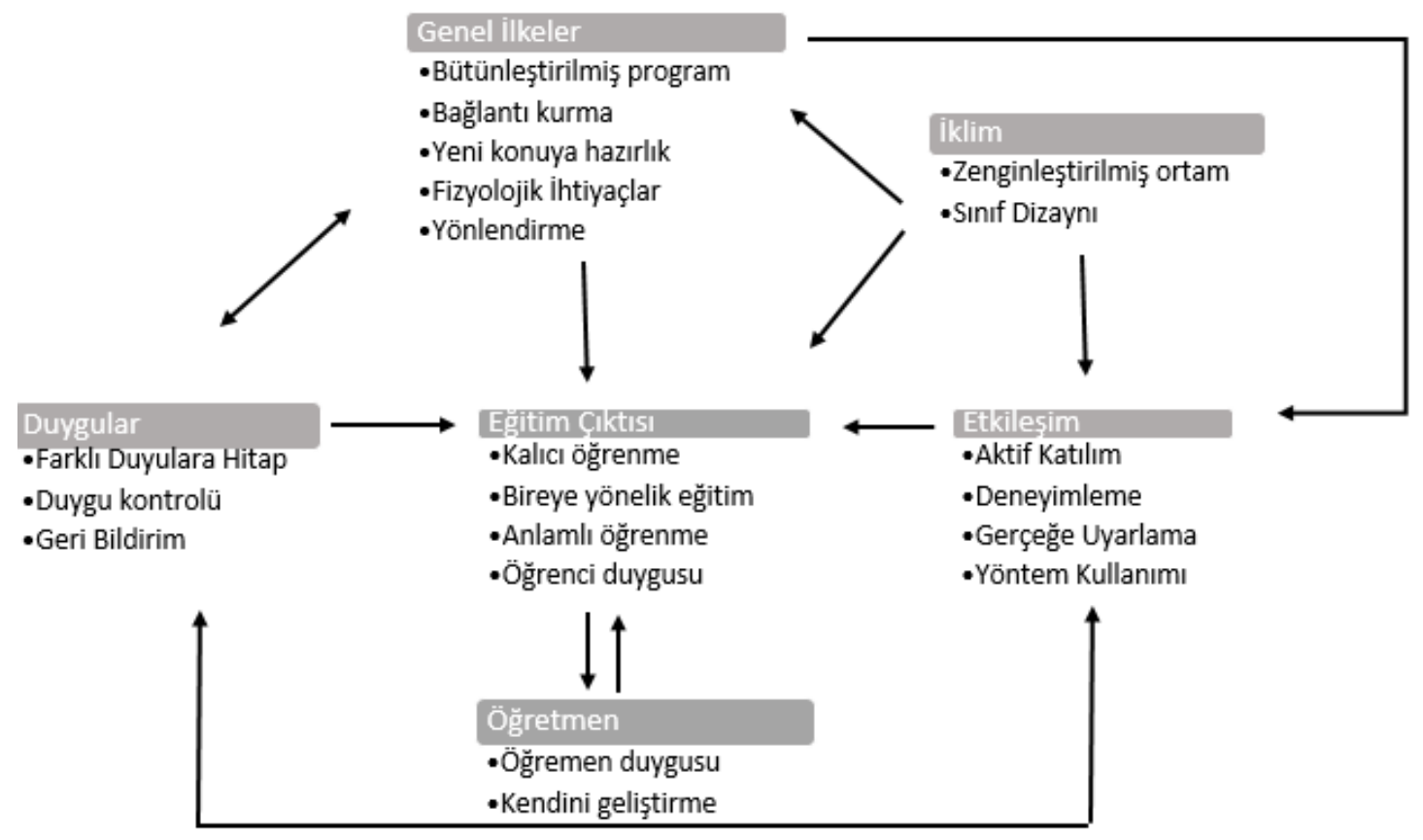

Şekil 1. Eksenel kodlama 
K6 kodlu 16 yıllık kadın öğretmenin etkileşim kategorisi altında bulunan aktif katılım ve iklim kategorisinde yer alan zenginleştirilmiş ortamın kalıcı öğrenme eğitim çıktısına etkisi ile ilgili görüşleri;

“...Aktif öğrenme ve sınıfta kullandığımız farklı materyallerle öğrenme destekleniyor. Bence çocuğa sunduğumuz materyallerle yani görsel dokunsal olan şeylerle ve çocuğun aktif katılımı, deneyimleme yapması ile konuların daha çok beyinde kaldığını düşünüyorum."

K4 kodlu 4 yıllık Erkek öğretmenin ifadelerinden öğrenci duyguları, eğitim çıktısı ve öğretmen kodları ile ilgili ilişki görülmektedir:

“..Etkinliklerimizin sayısını arttırıyoruz ve bunların daha çok duyu organına hitap edecek şekilde olmasına dikkat ediyoruz. Görsel zekası iyi olanlar için video izleterek veya bazı resimler göstererek destekliyoruz. Çünkü inanıyorum ki böylece öğrenci öğrendiklerini anlamlandırıyor ve sonra unutmuyor bu durumda benim öğretmen olarak mutlu olmamı sağlayan şey."

Eksenel kodlama sonrasında Şekil 2'de görüldüğü gibi “ideal öğrenme çıktısını” davranışlar, eğitim programları ve iklim olmak üzere üç ana faktörün etkilediği belirlenmiştir. Davranışlar; aktif katılım, deneyimleme ve bağlantı kurma olarak öğrencilerin davranışları ile ilgili faktörü oluşturmaktadır. Eğitim programı, eğitim-öğretim süresince öğretmenin uyguladığı bütünleşik program, kullandığı yöntem ve teknikler, yeni konuya geçişte yapılanlar, öğrenciyi yönlendirme davranışları ve öğrenciye verdiği geri bildirimleri ifade etmektedir. İklim ise farklı materyallerin kullanıldığı zenginleştirilmiş ortam, sınıfta yapılan düzenlemeler, farklı duyular için oluşturulan düzenlemeler ve öğrencilerin kızgın ya da üzgün oldukları zaman duygularının kontrolü için yapılan düzenlemeleri içermektedir.

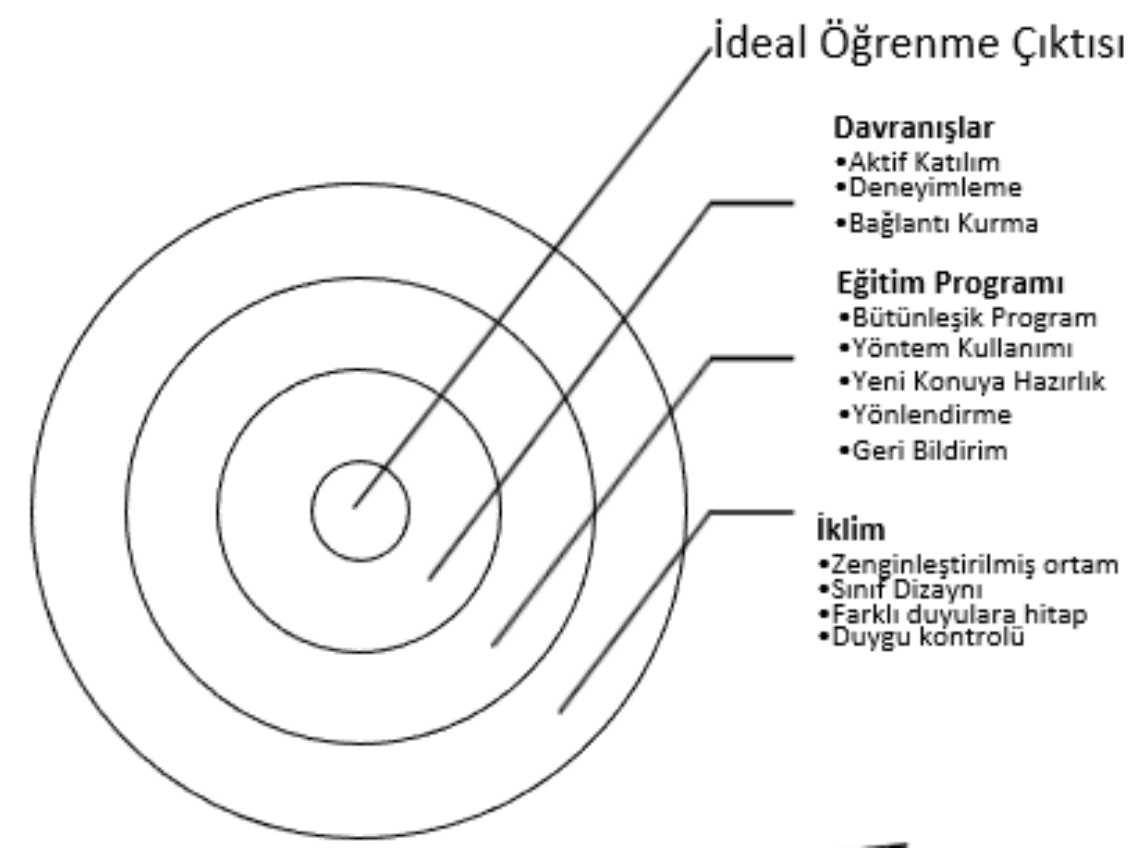

\section{Şekil 2. Seçici kodlama}

Seçici kodlamada iklim faktörünün; ideal öğrenme çıktısını, davranışları ve eğitim programını etkilediği, eğitim programının ise davranışlara da yansıdığı görülmektedir.

\section{Tartışma, Sonuç ve Öneriler}

Yapılan çalışmada görüşmeler ile toplanan veriler açık kodlama, eksenel kodlama ve seçici kodlama ile analiz edilmiştir. Analizler sonucunda, okul öncesi öğretmenlerin beyin temelli öğrenmeye yönelik düşünceleri belirlenmiştir.

Açık kodlama sonucunda; bilgi, uygulama ve değerlendirme olmak üzere üç ana kategori belirlenmiştir. Öğretmenler bilgi düzeyinde çok fazla yorum yapmazken uygulamada bu yöntemi kullandıklarını dile getirmişlerdir. Uygulama kategorisinde öne çıkan kodlar şu şekildedir: Bütünleştirilmiş program kullanımı, öğrencilere konuların tahmin ettirilmesi, yeni konuya geçileceği konusunda bilgi verilmesi ve yeni konuya geçişte çevre düzenlemesi yapılması tüm öğretmenler tarafından yapılmaktadır. BTÖ bileşenlerinden düzenlenmiş daldırmada öğretmenin, öğrencileri uygun aktivitelere çekebilmesi beklenmektedir. Bu aşama da bilim, matematik, sanat, tarih gibi konular bütünleştirilmelidir (R. N. Caine ve Caine, 1990). Bu nedenle tüm öğretmenlerin bütünleştirilmiş program kullanımı yöntem açısından uygun bir davranış olarak değerlendirilebilir. Beyin temelli öğrenmede her 
beynin eşsiz olduğu ve ön bilgilerin yeni öğrenmelere temel oluşturduğu dikkate alınmaktadır (Fogarty, 2002). Yapılan çalışmada da öğretmenlerin \%90'ının öğrencilerin ön bilgileri ile yeni öğrendikleri arasında bağlantı kurmaya çalıştıkları belirlenmiştir. Daha etkili öğrenmenin gerçekleştirilebilmesi için öğrencilerin önceki bilgileri ile yeni öğrenecekleri arasında ilişkilendirilme kurulması son derece önemlidir (Nummela ve Rosengren, 1986). Çünkü yeni bilgi ve deneyimler, geçmişte öğrenilenlerle ilişkilendirilmezse tekrar ve ezberleme ihtiyacı artmaktadır (R. N. Caine ve Caine, 1990). Öğrencilerin öğrenme sürecinde deneyimleme fırsatı bulması da öğretmenlerin \%80'i tarafından dile getirilmiştir. Kullanılan yöntem ve tekniklerde en çok işbirliğine dayalı öğrenmenin yer aldığı görülmektedir. BTÖ’de işbirliğine dayalı aktivitelerin önemi vurgulanmaktadır (R. N. Caine ve Caine, 1990; Jensen, 2008). Öğretmenlerin farklı duyulara hitap etmeye dikkat ettiği, en fazla görsel ve dokunsal duyulara hitap edildiği belirlenmiştir. Daha fazla duyu organına hitap etmek, daha fazla bilgi, daha verimli öğrenme süreci, öğrenilen bilgilerin bulunmasında daha fazla yol anlamına geldiği için eğitimin daha etkili olmasını sağlar (Katai, Toth, ve Adorjani, 2014). Öğretmenlerin, olumsuz geri bildirim vermeme eğiliminde oldukları görülmektedir. Sınıfta yapılması gereken düzenlemeler bulunmaktadır. Sınıf ortamında havalandırma, uygun ışık, ısı ayarının sağlanması, zenginleştirilmiş bir ortam oluşturma gibi fiziksel düzelmemelere dikkat edildiği görülmüştür. Bunun yanı sıra öğrencilerin sınıfta yaşadıkları duygusal durumlarda öğretmenlerin çoğunun olayın nedenini araştırdıkları ve farklı şekillerde öğrenciye duygusal destek sağlandıkları belirlenmiştir. Öğrenci merkezli yöntemlerde eğitimciler, sınıf ortamının fiziksel, sosyal ve duygusal yönler içermesini sağlanmalıdır (Kaufman vd., 2008). Öğretmenler, öğrencilerin sağlıklı ve dengeli beslenmesi, su içmesi gibi konularda onları desteklediklerini dile getirmişlerdir. Farklı çalışmalarda, yağ alımının fazla olmamasının, dengeli beslenmenin, B12 ve A vitaminin beyin, hafıza ve öğrenme açısından önemini vurgulamaktadır (Jensen, 2005). Yine sağlıklı beslenme ile ilgili olarak demir eksikliği olan çocukların, sağlıklı çocuklara göre matematik başarısının alt seviyede olma ihtimalinin iki kat fazla olduğu belirlenmiştir (Halterman, Kaczorowski, Aligne, Auinger, ve Szilagyi, 2001). Bu nedenle beslenme konusu önemli görülmektedir. Araştırmaya katılan öğretmenler; kalıcı bilginin oluşması için öğrencilerin aktif katılımlarının, konularda tekrarın sağlanmasının, anlamı öğrenme ve bağlantı kurmanın gerektiğini düşünmektedirler. İyi bir öğrenme ortamının gereklilikleri arasında da aktif katılım bulunmaktadır (Dwyer, 2002). Bilgilerin kısa süreli bellekten uzun süreli belleğe aktarılabilmesi için zihinsel tekrar ve kodlama yapılması bilginin uzun süreli belleğe aktarılmasını kolaylaştırabilir (Senemoğlu, 2011). Açık kodlamada belirlenen kodlara benzer şekilde Kaufman vd. (2008) farklı çalışmalardan yola çıkarak öğretmenlerin içerik de ilişki oluşturması, öğrenme sürecinde öğrencilerin aktif olmasını sağlaması, farklı öğrenme stilleri kullanması, öğretmen merkezli öğrenmeden öğrenci merkezli eğitime geçmesi sayesinde beyin temelli öğrenme stratejilerinin kullanımının sağlanabileceğini ifade etmiştir. Connell (2005) ise bu çalışmadaki kodlara benzer nitelikte olan bazı durumları şu şekilde derlemiştir. Öğrenme sürecinde, güvenli sınıf ortamını oluşmasının, teşvik edici ve ilgi çekici sınıf ortamının sağlanmasının, çeşitli öğretim metotları kullanımının, öğrencilerin su içmeye teşvik edilmesinin, gün boyunca hareket etmenin, florasan olmayan ışıklandırmanın kullanılmasının, stresin azaltılmasının, gün boyunca düşünme zamanın sağlanmasının gerekli ve önemli olduğu belirlenmiştir.

Açık kodlamanın değerlendirme kategorisinde ise öğretmenler farklı yöntem kullanımın dikkat çekme, tüm öğrencilere hitap eden bir eğitim süreci yaşama, yetenek geliştirme gibi faydaları olacağını düşünmektedirler. Bu yöntemin avantajları arasında ise kalıcı öğrenme, herkese hitap edebilme, deneyim fırsatı sağlamanın ilk akla gelenler olduğu görülmektedir.

Eksenel kodlamada kodlar arasında ilişkilendirmeler gerçekleştirilmiştir. Öğretmenlerin genel olarak dikkat ettiği durumlar "genel ilkeler", öğrenci duyguları ile ilgili yapılanlar "duygular", sınıf ortamı "iklim”, öğrenciler tarafında gerçekleştirilen uygulamalar "etkileşim", eğitim sonucunda oluşanlar "eğitim çıktısı" ve öğretmenle ilişkili durumlar "öğretmen” kategorisinde yeniden düzenlenmiştir. Birçok kategorinin birbiri ile ilişkili olduğu görülmektedir. Her bir kategorinin eğitim çıktısını etkilediği belirlenmiştir. Genel ilkelerin uygulanmasında, iklim ve duyguların etkisinin olduğu genel ilkelerin duygular ve etkileşimde yansımasının olduğu belirlenmiştir.

Seçici kodlamada ise ideal öğrenme çıktısına etkisi olan 3 etken tespit edilmiştir. Öğrenci davranışlarının, öğretmenin eğitim sürecinde yaptığı uygulamaları içeren eğitim programının ve iklimin, ideal öğrenme çıktısında etkili olduğu belirlenmiştir. Ayrıca davranışlarda ve eğitim programında iklimin etkisi, eğitim programının da davranışlara etkisi olduğu tespit edilmiştir. Fogarty (2002) ise beyin uyumlu sınıflarda dört temel unsurdan bahsetmektedir. Etkileşimin, iklimin, becerilerin ve üstbilişin yüksek başarı standartlarını sağlayacağını ifade etmektedir. Etkileşim, aktif katılım ve deneysel öğrenmeyi, iklim duyguları ve zenginleştirilmiş ortamı, beceriler mikro-makro becerileri ve becerilerin geliştirilmesini, üstbiliş ise yansıma ve değerlendirmeyi içermektedir. Yapılan çalışma ile de uyuşan yanlarının bulunduğu görülmektedir.

Sonuç olarak okul öncesi öğretmenlerin düşüncelerine göre öğrencilerin ideal öğrenme çıktısına ulaşabilmesi yapılması gereken temel işlemler bulunmaktadır. Bu amaca ulaşabilmek için öğrencilerin aktif katılım sağlaması, deneyimleme yaşaması, öğrendikleri arasında bağlantısı kurması gerekmektedir. Öğretmenlerin eğitim sürecinde bütünleşik öğrenmeyi gerçekleştirmesi, farklı yöntemler kullanması, yeni konuya geçiş yaparken hazırık yapması, öğrencilere gerekli yönlendirmeleri sağlaması, verdikleri geri bildirimlerin olumlu olması beklenmektedir. Bunların yanı sıra zenginleştirilmiş bir ortamın sağlanması, sınıf ortamında düzenlemelerin yapılması, farklı duyu organlarına hitap edilmesi ve öğrenci duygularının kontrolünde yapılması gerekenlerin olduğu görülmüştür.

Çalışma sonunda şu öneriler ortaya çıkmıştır; Eğitimde kullanılabilecek önemli yöntemlerden biri beyin temelli öğrenmedir. Kullanılan yöntemin ismi çok ön planda olmasa da eğitim sürecinde eğitmenlerin dikkat etmesi gereken bazı düzenlemeler olduğu bilinmektedir. Bu düzenlemeler arasında şunlara dikkat edilmesi gerekmektedir: öğrencilerin aktif katılımları teşvik edilmeli, yaptıkları çalışmaları gerçek bağlamda deneyimleme fırsatı oluşturulmalı, öğrendikleri konu ile ön bilgileri arasında bağlantılar 
kurulmalıdır. Farklı dersler birbirleri ilişkilendirilmeli ve kendi içlerinde bağlantılar kurulmalı, işbirliğine dayalı öğrenme, soru sorma, beyin fırtınası gibi farklı yöntem ve teknikler kullanılmalı, yeni konuya geçileceği zaman gerekli düzenlemeler yapılmalı, öğrencilere olumlu geri bildirimler sağlanmalıdır. Sınıflarda farklı materyaller kullanılmalı, sınıf düzenlemesi yapılırken ilgi çekici bir ortamın yanı sıra fiziksel düzenlemelere dikkat edilmeli, görsel öğeler yerleştirilmeli, eğitim sürecinde olabildiğince fazla duyu organına hitap edilmelidir. Öğrencilerin fizyolojik ihtiyaçlarının giderilmesi sağlanmalıdır.

\section{KAYNAKÇA}

Açıkgöz, K. Ü. (2003). Etkili öğrenme ve öğretme. İzmir: Eğitim Dünyası Yayınları.

Akyurek, E.,\& Afacan, O. (2013). Effects of brain-based learning approach on students' motivation and attitudes levels in science class. Online Submission, 3(1), 104-119.

Avcı, D. E., \& Yağbasan, R. (2010). Beyin temelli öğrenme hakkında öğrenci görüşleri. Kastamonu Eğitim Dergisi, 18(1), 1-18.

Caine, G., \& Caine, R. N. (1989). Learning about accelerated learning. Training \& Development Journal, 43(5), 64-74.

Caine, R. N., \& Caine, G. (1990). Understanding a brain-based approach to learning and teaching. Educational Leadership, 48(2), 66-70.

Connell, J. D. (2005). Brain-based strategies to reach every learner. U.S.A: Scholastic Teaching Resources.

Dwyer, B. M. (2002). Training strategies for the twenty-first century: using recent research on learning to enhance training. Innovations in Education and Teaching International, 39(4), 265-270. https://doi.org/10.1080/13558000210161115

Erol, M., \& Karaduman, G. B. (2018). The effect of activities congruent with brain based learning model on students' mathematical achievement. NeuroQuantology, 16(5), 13-22.

Fogarty, R. (2002). Brain compatible classrooms. (Skylight P). IL.

Gozuyesil, E., \& Dikici, A. (2014). The effect of brain-based learning on academic achievement: a meta-analytical study. Educational Sciences: Theory and Practice, 14(2), 642-648.

Halterman, J. S., Kaczorowski, J. M., Aligne, C. A., Auinger, P., \& Szilagyi, P. G. (2001). Iron deficiency and cognitive achievement among schoolaged children and adolescents in the United States. Pediatrics, 107(6), 1381-1386.

Hileman, S. (2006). Motivating students using brain-based teaching strategies. Agricultural Education Magazine, 78(4), 18.

Jensen, E. (2005). Teaching with the brain in mind. (2 nd.). Alexandria, Virginia USA: Association for Supervision and Curriculum Development (ASDC).

Jensen, E. (2008). Brain-based learning: The new paradigm of teaching. Thousand Oaks, CA: Corwin Press.

Katai, Z., Toth, L., \& Adorjani, A. K. (2014). Multi-sensory informatics education. Informatics in Education, 13(2), $225-240$.

Kaufman, E. K., Robinson, J. S., Bellah, K. A., Akers, C., Haase-Wittler, P., \& Martindale, L. (2008). Engaging students with brain-based learning. Techniques, 83(1), 50-55.

Koyuncu, B., \& Erden, M. (2010). Zenginleştirilmiş beyin uyumlu öğretim ortamına ilişkin öğrenci görüşleri. Kuram ve Uygulamada Eğitim Yönetimi Dergisi, 16(1), 73-92.

LeCompte, M. D., \& Goetz, J. P. (1982). Problems of reliability and validity in ethnographic research. Review of Educational Research, 52(1), 3160.

Mastoni, E., Sumantri, M. S., \& Ibrahim, N. (2019). A preliminary study of brain-based learning (bbl) and ıntrapersonal ıntelligence in junior high school mathematics learning. Universal Journal of Educational Research, 7(9A), 147-154.

Mastropieri, M. A., \& Scruggs, T. E. (1998). Enhancing school success with mnemonic strategies. Intervention in School and Clinic, 33(4), 201208.

Miles, M. B., \& Huberman, A. M. (1994). Qualitative data analysis. CA: Sage Publications.

Noureen, G., Awan, R. N., \& Fatima, H. (2017). Effects of brain based learning on academic achievement of VII graders in Mathematics. Journal of Elementary Education, 27(2), 85-97.

Nummela, R. M., \& Rosengren, T. M. (1986). What's happening in students' brains may redefine teaching. Educational Leadership, 43(8), 49-53. 
Oktay, S., \& Çakır, R. (2013). Academic achievement, retention level and metacognitive awareness. Journal of Turkish Science Education, 10(3), $3-23$.

Özden, M., \& Gültekin, M. (2008). The effect of brain based learning on academic achievement and retention of knowledge in science course. Electronic Journal of Science Education, 12(1), 1-17.

Palavan, Ö., \& Demir, H. (2017). Sınıf öğretmenlerinin beyin temelli öğrenmeye yönelik görüşleri. Siirt Üniversitesi Sosyal Bilimler Enstitüsü Dergisi, 5(8), 99-132.

Politano, C., \& Paquin, J. (2000). Brain-based learning with class. Canada: Portage \& Main Press.

Punch, K. F. (2011). Sosyal araştırmalara giriş. nicel ve nitel yaklaşımlar. Ankara: Siyasal.

Saleh, S. (2011). The effectiveness of the brain-based teaching approach in generating students' learning motivation towards the subject of physics: a qualitative approach. Online Submission, 1, 63-72.

Saleh, S., \& Subramaniam, L. (2018). Effects of brain-based teaching method on physics achievement among ordinary school students. Kasetsart Journal of Social Sciences., 1-5.

Sausa, D. A. (2001). How the brain learns: a classroom teacher's guide. California: Corwin Pres.

Senemoğlu, N. (2011). Gelişim öğrenme ve öğretim kuramdan uygulamaya (20.). Pegem Yayınevi,.

Shabatat, K., \& Al-Tarawneh, M. (2016). The impact of a teaching-learning program based on a brain-based learning on the achievement of the female students of 9th grade in chemistry. Higher Education Studies, 6(2), 162-173.

Strauss, A., \& Corbin, J. (1990). Basics of qualitative research: grounded theory procedures and techniques. London: Sage Publications.

Thomas, B. M., \& Swamy, S. S. (2014). Brain based teaching approach: A new paradigm of teaching. International Journal of Education and Psychological Research, 3(2), 62-65.

Tosun, C., \& Yaşar, M. D. (2015). Descriptive content analysis of problem-based learning researches in science educaion in Turkey. Kastamonu Eğitim Dergisi, 23(1), 293-310.

Tüfekçi, S., \& Demirel, M. (2009). The effect of brain based learning on achievement, retention, attitude and learning process. Procedia-Social and Behavioral Sciences, 1(1), 1782-1791.

Uzezi, J. G., \& Jonah, K. J. (2017). Effectiveness of brain-based learning strategy on students' academic achievement, attitude, motivation and knowledge retention in electrochemistry. Journal of Education, Society and Behavioural Science, 21(3), 1-13.

Willis, J. (2007). Review of research: Brain based teaching strategies for improving students' memory, learning and test-taking success. Childhood Education, 83(5), 310-315. https://doi.org/10.1080/0094056.2007.10522940

Yasar, M. D. (2017). Brain Based learning in science education in turkey: descriptive content and meta analysis of dissertations. Journal of Education and Practice, 8(9), 161-168. 